Article

\title{
An Adaptive Energy Optimization Method of Hybrid Battery-Supercapacitor Storage System for Uncertain Demand
}

\author{
Xiaomin $\mathrm{Wu}^{1,2, * \mathbb{D}}$, Shaoyi $\mathrm{Li}^{1}{ }^{1}$, Shengfeng Gan ${ }^{1}$ and Changhui Hou ${ }^{1}$ \\ 1 School of Artificial Intelligence, Nanchang Institute of Science \& Technology, Nanchang 330108, China; \\ lisy@ncpu.edu.cn (S.L.); sf_gan@163.com (S.G.); hch5279886@163.com (C.H.) \\ 2 State Grid Hubei Electric Power Research Institute, Wuhan 430077, China \\ * Correspondence: wxm@cug.edu.cn; Tel.: +86-27-8566-6662
}

check for updates

Citation: Wu, X.; Li, S.; Gan, S.; Hou, C. An Adaptive Energy Optimization Method of Hybrid Battery-

Supercapacitor Storage System for Uncertain Demand. Energies 2022, 15 , 1765. https://doi.org/10.3390/ en15051765

Academic Editor: Suhail Hussain and Taha Selim Ustun

Received: 27 January 2022

Accepted: 24 February 2022

Published: 27 February 2022

Publisher's Note: MDPI stays neutral with regard to jurisdictional claims in published maps and institutional affiliations.

Copyright: (c) 2022 by the authors. Licensee MDPI, Basel, Switzerland. This article is an open access article distributed under the terms and conditions of the Creative Commons Attribution (CC BY) license (https:// creativecommons.org/licenses/by/ $4.0 /)$.

\begin{abstract}
To address the problem of DC bus voltage surge caused by load demand fluctuation in an off-grid microgrid, here, an adaptive energy optimization method based on a hybrid energy-storage system to maintain the stability of DC bus voltage is presented. The adaptive energy optimization method consists of three parts: the average filtering algorithm, extracting fluctuating power in demand load; the supercapacitor terminal voltage control, keeping the terminal voltage of the supercapacitor near reference; and the battery pack balance control, adjusting the charge/discharge to balance the state of charge for battery packs. In this proposed method, after extracting the fluctuating power by the low-pass filter when the demand load fluctuates, the battery packs release the power to offset the low-frequency fluctuation load and the supercapacitor to instantaneously compensate the high-frequency fluctuation power, to prolong the service life of batteries and maintain the stability of DC bus voltage. The effectiveness of the proposed adaptive energy optimization method is validated and is confirmed to maintain the stable operation of the off-grid microgrid, extend the cycle life of batteries in off-grid microgrid simulations and experiments.
\end{abstract}

Keywords: hybrid energy storage system; adaptive energy optimization; fluctuation load; supercapacitor; battery pack

\section{Introduction}

The reliability and plentiful supply of electricity is one of the essential requirements in the development of the economy and technology, and using a microgrid based on renewable energy sources (RES) is one of the effective ways to improve the strength of the traditional grid [1]. Many distributed generators (DG) have direct current (DC) output, and do not suffer from the problems of phase synchronization and reactive power loss. One difficulty is that the utilization of intermittent renewable energy resources in power supply poses several challenges [2]. The hybrid energy storage system (HESS) is a schedulable resource with the corresponding energy management scheme and control strategy, improving the transient and steady-state performance to address relevant problems in microgrid systems $[3,4]$.

As has been proven in the literature, using two or more types of storage devices to construct a hybrid energy storage system (HESS) provides a better performance than a storage system consisting of only one type of storage device. Compared with a supercapacitor (SC), the energy density feature of a battery is higher than an SC. Instead, the power density feature of an SC is higher than a battery. Both high energy density and high power density are components of the main performance of HESS. They are to provide power compensation during low-frequency oscillation, while being able to supply/absorb the transients' power on the high-frequency component. To provide reliable and plentiful power and maintain a stable microgrid system, the focus will be a solution on the HESS consisting of a battery and SC in this paper. 
A strong pulse load can cause large power fluctuations and impact the DC bus voltage and energy-storage devices; HESS can give full play to the characteristics of SC power density and battery energy density, to reduce the adverse effects of a fluctuation load $[5,6]$. The relevant literature shows that the SC can compensate the output current of the battery, relieve the pressure of the high-output battery current, reduce the battery terminal voltage drop and internal losses, and improve battery characteristics and extend its life [7-9]. In Ref. [10], an HESS energy-management method based on fluctuation characteristic parameters was proposed, while Ref. [11] proposed energy management based on fuzzy control to achieve power distribution among the SC and battery in a connected-grid microgrid. HESS energy management schemes are different according to the connection structure of the SC and battery, but the basic idea is to use the battery to bear the low-frequency component of the load, and the SC to suppress the high-frequency component [12-14].

A HESS application to suppress DGs power fluctuation has been achieved some research results. First, Ref. [15] proposed a control strategy that takes into the state of charge (SoC) of SC and the system power loss, to suppress the power fluctuation of the photovoltaic system. Another study, Ref. [16], proposed energy management based on power and voltage limitation methods to suppress DGs power fluctuation. However, methods based on limit measures lack adaptive dynamic adjustability. In Ref., [17] a method in which the output current participates in the compensation of the current loop was proposed, which improves the stability of the bus voltage. Meanwhile, Ref. [18] compared the power feedforward control strategy with the direct power control strategy for the SC energy storage, and showed that the latter can better suppress the DC bus voltage fluctuation. Finally, Ref. [19] used a first-order low-pass filtering method to filter DGs power fluctuation, but this was sensitive to the typical characteristics of power fluctuation such as fluctuation loads and has a slightly poorer applicability.

Most of the aforementioned literature focuses on suppressing power fluctuation based on the method of storage device limits, to prevent overcharging or over-discharging for the energy-storage system in a grid-connected DC microgrid. However, there are few studies on the power balance of off-grid DC microgrid connected to the fluctuation load, the adaptive adjustment of storage energy SoC, and the operation optimal of an off-grid DC microgrid [20-22]. In [20], a management scheme is proposed for a hybrid energy-storage system with battery and supercapacitor energy storage as the core, and the designed scheme has adaptive characteristics. In Ref. [21], a power-distribution strategy that takes into account the charge state and system loss of supercapacitors was proposed, and the experimental effect of stabilizing photovoltaic power fluctuation was shown to be improved. Another study, Ref. [22], proposed a first-order low-pass filtering method to filter DG power fluctuations, but the sensitivity of low-pass filtering to the typical characteristics of power fluctuations, such as pulsating loads, and its applicability are slightly poorer. The power balance of an off-grid DC microgrid and the suppression of DG fluctuations are quite different. The requirements of the weak inertia of an isolated DC microgrid and the plug-and-play nature of fluctuation loads put forward higher requirements for energy-control strategies.

This paper aims to solve the problem in which the DC bus voltage fluctuation is caused by the power fluctuation of an off-grid photovoltaic microgrid. Based on the application research of HESS, an adaptive energy-optimization (AEO) method based on the filter algorithm, SC voltage adaptive control, and battery-pack balance control is proposed to scheme the HESS energy management and ensure the stable operation of an off-grid photovoltaic microgrid.

This paper is organized as follows: Section 2 presents the description and structure of the DC convert. The adaptive energy-optimization method and the design guidelines of a control strategy for the stable operation HESS are discussed in Section 3. The simulation results and analysis in Section 4 verify the proposed control strategy. 


\section{Off-Grid Microgrid and HESS}

\subsection{Off-Grid Microgrid Configuration}

The system structure of the off-grid microgrid is shown as Figure 1, which consists of a DG (Photovoltaic), supercapacitor module, battery module, DC converter, and adjustable load [23]. The photovoltaic system (PV) is linked to the DC bus by the DC converter 1. The SC module and the battery module are connected by line to the DC bus by the DC converter 2 and the multiport DC converter, respectively. The adjustable load includes the fixed load and pulsating load, and is fed directly into the DC bus. In this paper, we focus on HESS energy management in the off-grid microgrid. As shown in Figure 1, the generation power of the photovoltaic system is defined $P_{p v}$, the output power of the SC module is defined $P_{S C}$, and the output power of the battery module is defined $P_{B a t}$. The $P_{\text {load } 1}$ and $P_{\text {load } 2}$ represents the fixed load and the fluctuation load, respectively. The power balance of the off-grid microgrid is expressed by:

$$
P_{\text {load }}-P_{p v}=P_{S C}+P_{B a t}
$$

The DC converter 1 uses the maximum-power point-tracking method to improve the generation power of the PV system. The DC converter 2 is a bidirectional buck/boost converter, and meets the charging and discharging performance of the SC module with high power in a short time. The multiport DC converter is formed by the bidirectional converter in parallel while improving the power transmission of the battery module for a long time, and it not only reduces the performance requirements of the single buck/boost converter on the switch tube but also avoids the circulation current problem caused by the large-scale battery string series-parallel connection.

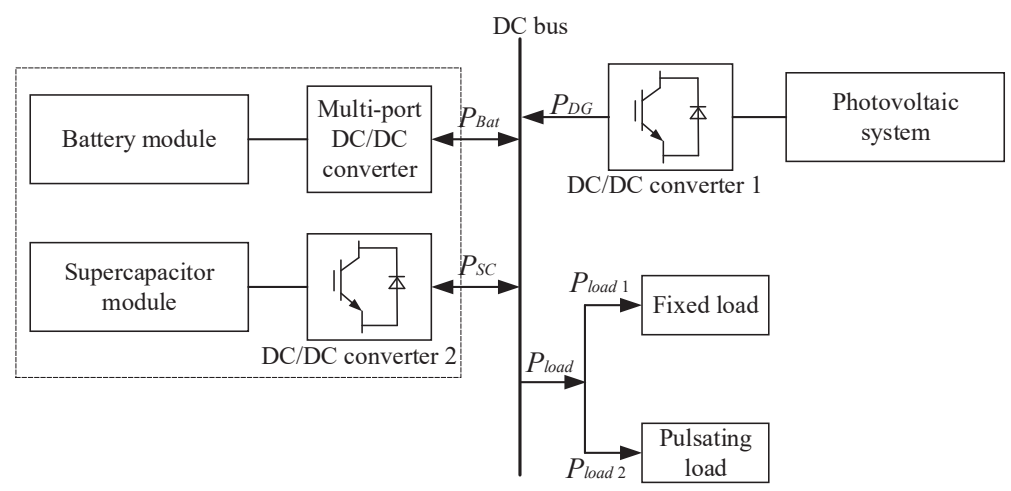

Figure 1. Off-grid microgrid system.

\subsection{Structure and Control Principle of HESS}

Figure 2 shows the structure of the HESS and control principle. To simplify the structure of the HESS and consider the randomness of the photovoltaic, the $R_{\text {load } 2}$ is equivalent to the generation power of the PV system and the fluctuation load. $S_{w 1}-S_{w 4}$ are the DC circuit breaker to control the switching of each port. $K_{1}-K_{4}$ are the protective circuit breaker which is normally closed after turn-on, disconnected when overvoltage, overcurrent, and other faults occur. $R_{s}$ is the turn-on resistance, cooperating with $K_{1}$ during the turn-on to avoid the starting instant impact of inrush current on the device. $L_{i 1}-L_{i 4}$ are the energy storage inductance. $C_{S C}$ and $C_{B a t}$ are the filter capacitor. $S_{R 1}$ and $S_{R 2}$ are the load circuit breaker. $R_{\text {load } 1}$ and $R_{\text {load } 2}$ represent the fixed load and the fluctuation load, respectively. $U_{S C}$ and $U_{B a t}$ are the terminal voltage of the SC module and the battery module, and the $i_{S C}$ and $i_{B a t}$ are the charging/discharging current of the SC module and the battery module. $U_{d c}$ is the DC bus voltage of the off-grid microgrid, $i_{l o a d}$ is the load current, and $\sigma_{S o C, B a t}$ is the SoC of the battery module.

The HESS energy management system implements a control strategy according to the voltage $\left(U_{S C}, U_{B a t}, U_{d c}\right)$, the current $\left(i_{B a t}, i_{\text {load }}\right)$ and the switches' states, to monitor and 
adjust the SoC of the SC module and the battery module. In the HESS energy-management system, the multiport DC/DC converter of the battery module uses the current closedloop control, and the DC/DC converter 2 of the SC module uses the voltage closed-loop control. As shown in Figure 3, $U_{d c_{-} r e f}$ and $I_{B a t \_r e f}$ are the reference voltage of the DC bus and the reference charging/discharging current of the battery pack 1, respectively. $U_{d c}$ is the DC bus voltage, $I_{B a t 1}$ is the filtering current of the battery pack 1 . The pulse-width modulation (PWM) signal is determined by after compared the duty ratio $D_{S C}$ or $D_{B a t}$ with the triangular carrier wave ratio.

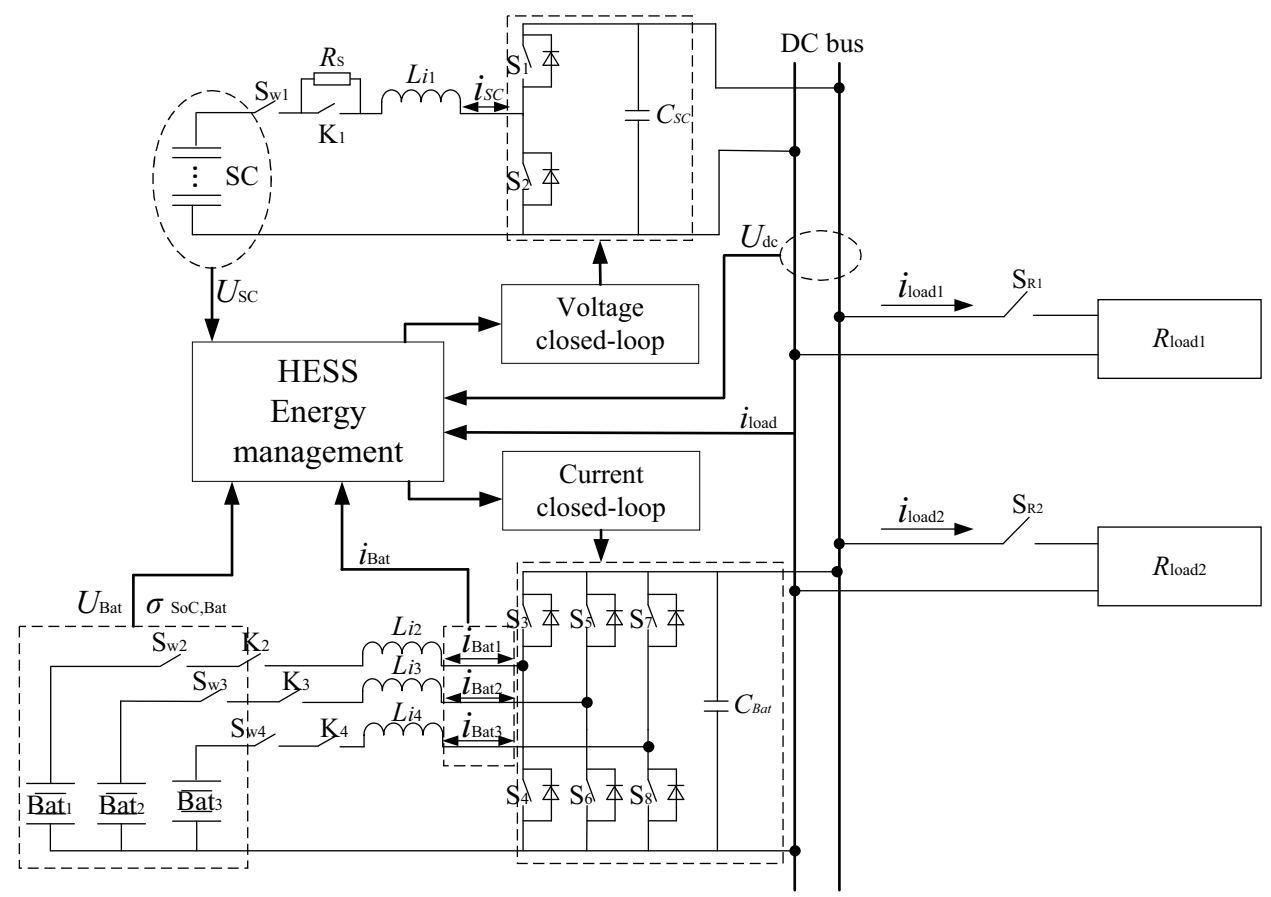

Figure 2. The control diagram of the HESS.

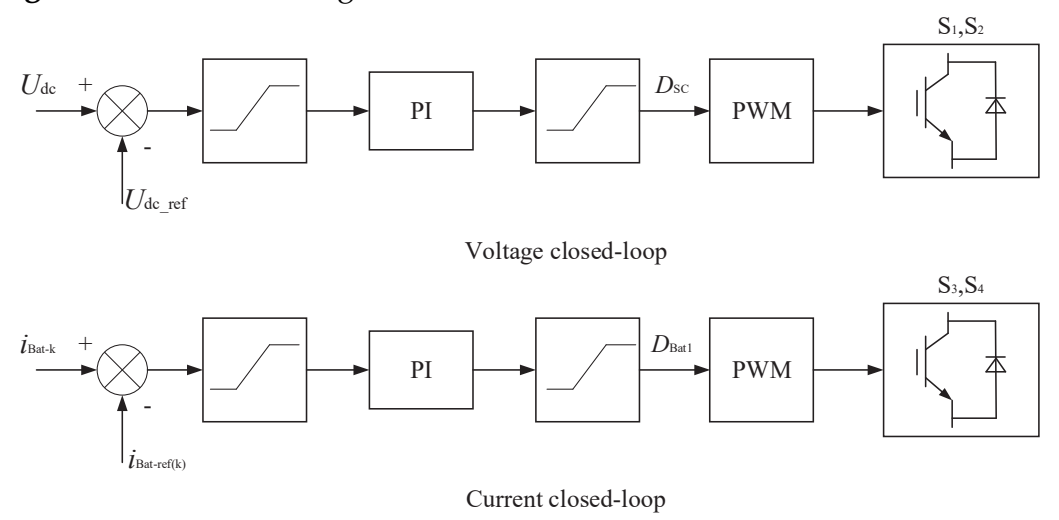

Figure 3. The voltage closed-loop and the current closed-loop of HESS converter.

\section{Adaptive Energy Optimization Method}

The adaptive energy optimization (AEO) method is proposed based on the filter algorithm, SC voltage adaptive control, and battery-pack balance control, as shown in Figure 4. The AEO aims to optimize the charging/discharging of the battery module and adjust the SC module terminal voltage near the reference voltage. First, the filtering algorithm is used to obtain the $P_{\text {load } 2}$ for the fluctuation load. Adaptive voltage control is introduced, so the transmission power of the battery pack can be adjusted in real-time according to the SC module terminal voltage, and the compensation power $P_{\text {com }}$ can be obtained. Then, the actual load $P_{\text {load1 } 1}$, the fluctuation load $P_{\text {load2 }}$, and the compensation power $P_{\text {com }}$ are added to calculate the transmission power $P_{B a t}$ of the battery pack. Finally, 
the transmission power $P_{B a t}$ is distributed to each battery pack in the current closed-loop control according to the battery-pack balance control. The difference between the load $P_{\text {load }}$ and the battery module transmission power is compensated by the SC module through the voltage closed-loop control.

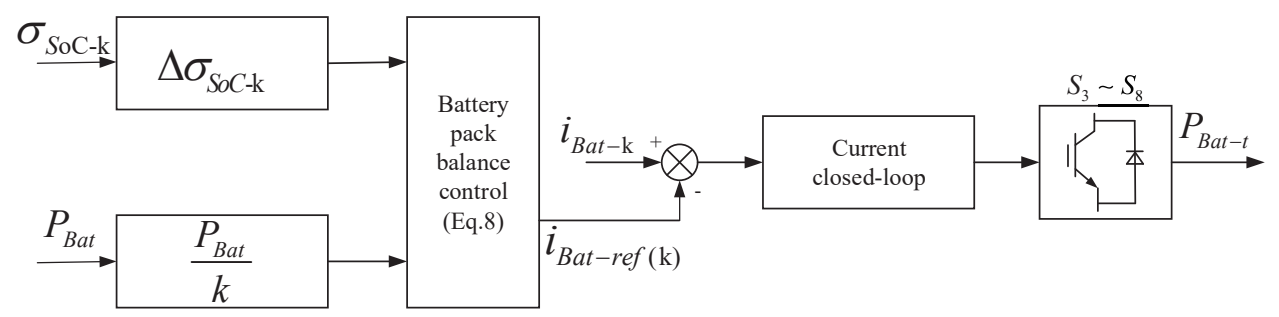

Figure 4. The balance control diagram of the battery module.

\subsection{Average Filtering Algorithm}

The average filtering algorithm is based on a moving average of several sequential values to calculate a new sequence of average values [24]. In a sliding window with a fixed time $T$, new data are always in the front of the sliding window, and old data are removed from the window at each sampling interval. The average filtering algorithm is expressed by:

$$
y[n]=\frac{1}{T / t} \sum_{k=0}^{T / t-1} x(n-k)
$$

where $T$ is the sliding window time width, $t$ is the sampling interval. As shown in Figure 4, the fluctuation load current $i_{\text {load } 2}$ and the DC bus voltage are integrated in the sliding window $T$, and obtain a smoother power $P_{\text {load } 2}$. Therefore, the time width $T$ of the sliding window is necessarily reasonable to set.

The fluctuation load can be decomposition according to the Fourier, and expressed as follow:

$$
f(t)=\frac{4 E}{\pi}\left(\cos \omega_{0} t-\frac{1}{3} \cos 3 \omega_{0} t+\frac{1}{5} \cos 5 \omega_{0} t-\cdots\right)
$$

To simplify the analysis, this paper only analyzes the amplitude-frequency characteristics of the first harmonic of the fluctuation load through the sliding window. The filter is expressed as follows:

$$
y(t)=\frac{1}{T} \int_{t-T}^{t} f(x) d x
$$

where $y(t)$ is the output of the filter, and $f(x)$ is the input signal of the filter. Let the input signal be the first harmonic of a square wave, and expressed by:

$$
f(t)=\cos \left(\frac{2 \pi}{T_{0}} t\right)
$$

where $T_{0}$ is the square wave period. Substituting the Equation (5) into Equation (4) can give:

$$
y(t)=\frac{1}{\omega_{0} T}\left[\sin \omega_{0} t\left(1-\cos \omega_{0} T\right)+\cos \omega_{0} t \sin \omega_{0} T\right]
$$

where $\omega_{0}=\frac{2 \pi}{T_{0}}$. In the case of considering only the effect of the first harmonic attenuation, $T \in\left[0.42 T_{0}, T_{0}\right]$ meets the requirements of harmonic attenuation.

The sliding average filter is equivalent to a second-order low-pass filter, and the secondorder low-pass filter gain attenuation is usually required in the project to be between 3 and $40 \mathrm{~dB}$. With only the 1st harmonic attenuation effect considered, it can be set as $0.42 T_{0}<T<T_{0}$. If the supercapacitor configuration capacity is more abundant, the attenuation of the harmonic can be increased, so that the supercapacitor can bear more 
pulsating power charge and discharge, set as $T \rightarrow T_{0}$. If the supercapacitor configuration capacity is small, it is set as $T \rightarrow 0.42 T_{0}$.

\subsection{Battery-Pack Balance Control}

The battery pack needs to meet the requirements of long-term energy supply. It is also important to consider the proper distribution of the output power for each battery pack port [25]. The distribution is based on the state of charge balance of each battery pack and the energy transfer efficiency of the HESS.

To determine the average $\mathrm{SoC}, \sigma_{\mathrm{So} \_\_a v e}$, of the battery pack port, the $\sigma_{S o C-k}$ is calculated the SoC of the battery pack $k$. The average SoC is expressed by:

$$
\sigma_{\text {SoC_ave }}=\frac{1}{k} \sum_{i=1}^{k} \sigma_{\text {SoC }-k}
$$

The balance control of the battery pack aims to make each battery pack SoCs consistent and determine each battery pack port transfer output power $P_{\text {Bat_ref }(k)}$ and reference current $i_{\text {bat_ref }(k)}$, as shown in Figure 4. The output power of each battery pack is calculated using the actual load demand and the adjusted power deviation considering the imbalance SoC of a battery pack. It is obtained as follows:

$$
\left\{\begin{array}{l}
P_{\text {Bat_ref }(k)}=\overline{P_{\text {Bat }}}+\eta_{0} \Delta \sigma_{S o C-k} \\
i_{\text {Bat_ref }(k)}=\frac{P_{\text {Bat_ref }}}{U_{\text {Bat }-k}}
\end{array}\right.
$$

where $\overline{P_{B a t}}$ is the average output power for each battery pack, $\eta_{0}$ is a gain coefficient of power deviation, the $U_{B a t-k}$ is the port voltage of battery pack $k$. The $\Delta \sigma_{S o C-k}$ is the imbalance degree of battery pack $k$, and can be expressed by:

$$
\Delta \sigma_{S o C-k}=\sigma_{S o C-k}-\sigma_{S o C \_a v e}
$$

\subsection{Supercapacitor Voltage Adaptive Control}

Due to the power loss and other factors in the HESS, the SC terminal voltage will deviate from its reference value. In severe cases, the HESS stops working when the SC terminal voltage reaches the limit [26]. Therefore, it is necessary to adjust the terminal voltage during SC operation. There is a definite relationship between the SC stored power $P_{s c}$ with the SC terminal voltage $U_{s c}$. Therefore, the SoC of SC is calculated according to the terminal voltage of SC and can be expressed by:

$$
S o C_{s c}=\frac{C_{s c} U_{s c}^{2} / 2}{C_{s c} U_{\text {rated }}^{2} / 2}=\left(\frac{U_{s c}}{U_{\text {rated }}}\right)^{2}
$$

where $P_{s c}=C_{s c} U_{s c}^{2} / 2, C_{s c}$ is the capacity of $\mathrm{SC}$, and $U_{s c}$ is the terminal voltage of $\mathrm{SC}, U_{r a t e}$ is the rated voltage of SC.

To prevent overcompensation, the adaptive control is maintained according to the SC terminal voltage $U_{s c}$ value. The voltage range of the SC module is divided into five control bands, and each control band area sets the corresponding lower and upper voltage and the gain factor. The output power of SC is different depending on the SC terminal voltage, as shown in Figure 5. According to the different accommodation coefficients, the output power of SC can be expressed as follows:

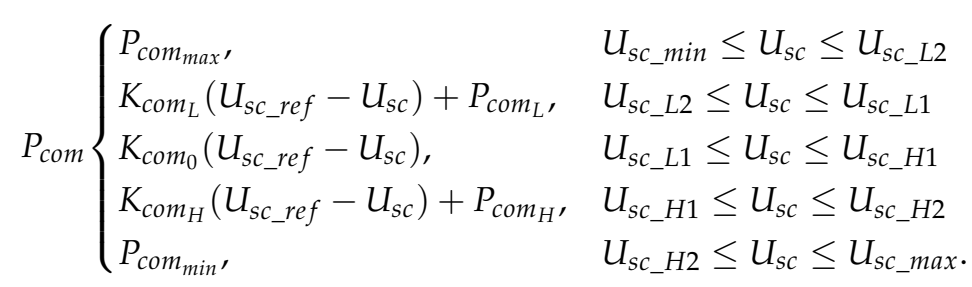


where $K_{\text {com }_{L}}, K_{\text {com }_{0}}$ and $K_{c o m_{H}}$ represent the different compensation coefficient; $P_{c o m}$ min and

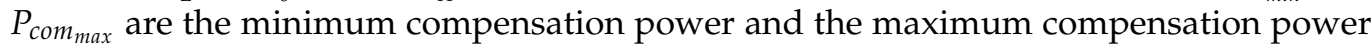
of the SC, respectively; $P_{c o m}$ and $P_{c o m}$ are the continuous compensation power at the different adjustment range. $U_{S C_{-} L 2}, U_{S_{-} L 1}, U_{S_{C_{-} H} H 1}$ and $U_{S_{-} H 2}$ are the corresponding lower and upper voltage of each control band.

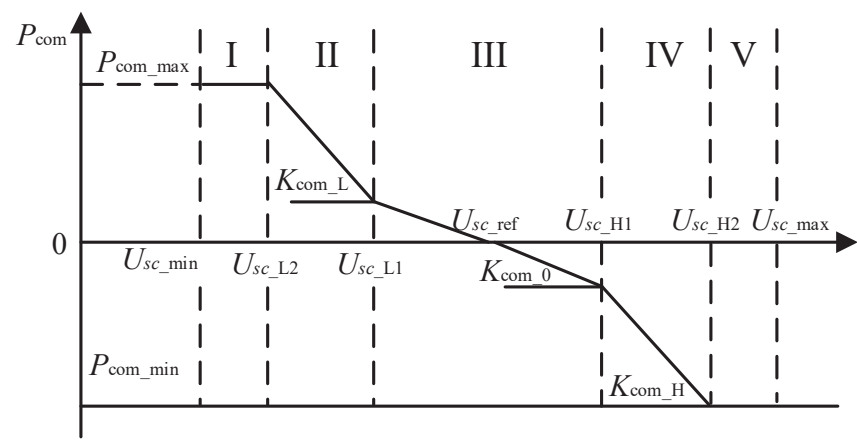

Figure 5. Diagram block of the SC module voltage adaptive control.

Setting a reasonable adjustment factor, the output power of the SC module is calculated using Equation (11). Therefore, the stable SC terminal voltage is achieved indirectly by the output power of the battery pack in the HESS.

\section{Results and Discussion}

To verify the effectiveness of the proposed adaptive energy optimization control strategy, a simulation test is using an off-grid DC microgrid, as shown in Figure 6. This off-grid DC microgrid system is composed of the actual wind-power-generation system, the actual photovoltaic power-generation system, the simulated wind-power-generation system, the hybrid energy-storage system, the microgrid central-control system, the programmable RLC three-phase load, the environmental monitor, and other main parts, as show in Table 1. The main function of the hybrid energy-storage system is a two-way converter with a stable control function, and when the microgrid is running in the isolated network, the device serves as the standard source of the microgrid system to ensure that the microgrid is in the process of isolated network operation and mode-switching system stability.

The parameters of the simulation experiment are as show in Table 2, the battery pack consists of 6 lead-acid batteries in series and the voltage range is $60-75 \mathrm{~V}$; the SC module is $75 \mathrm{~V} / 13.3 \mathrm{~F}$ and consists of 4 SCs in parallel, and the voltage range is 50-70 V. The energystorage inductor $L_{i 1}=1200 \mathrm{uH}$, and $L_{i 2}=L_{i 3}=L_{i 4}=800 \mathrm{uH}$. The turn-on resistance $R_{s}$ is setting $100 \Omega$, and the filter capacitor $C_{s c}$ and $C_{B a t}$ are set at $45 \mathrm{uF}$. In this off-grid microgrid, the fixed load is set to $1.8 \mathrm{~kW}$, the power range of the fluctuation load is set to $0-2 \mathrm{~kW}$. The reference voltage of the DC bus is setting $U_{d c_{-} r e f}=130 \mathrm{~V}$, and the reference voltage of the $S C$ module is setting $U_{S C_{-} r e f}=60 \mathrm{~V}$. The corresponding lower and upper voltage are sets $U_{S C_{-} L 2}=52 \mathrm{~V}, U_{S C_{-} L 1}=56 \mathrm{~V}, U_{S C_{-} H 1}=64 \mathrm{~V}$ and $U_{S C_{-} H 2}=68 \mathrm{~V}$, respectively. The switching frequency is $20 \mathrm{kHz}$, and the sampling frequency is $100 \mathrm{kHz}$.

Table 1. Microgrid system specifications.

\begin{tabular}{lcc}
\hline Subsystem & Rated & Specifications \\
\hline Wind turbine & $5 \mathrm{~kW}$ & $\mathrm{I}_{o p}=8.28 \mathrm{~A}, \mathrm{~V}_{o p}=30.2 \mathrm{~V}$ \\
Photovoltaic & $3 \mathrm{~kW}$ & $\mathrm{~V}_{o p}=48 \mathrm{~V}$ \\
Battery & $12 \mathrm{~V} / 50 \mathrm{Ah}$ & 30 group, Series \\
Ulreacapacitor & $7 \mathrm{~F} / 110 \mathrm{~V}$ & 2 group, Parallel \\
Bidirectional convert & $20 \mathrm{~kW}$ & $\mathrm{~V}_{\text {low }}=48 \mathrm{~V}, \mathrm{~V}_{\text {high }}=400 \mathrm{~V}$ \\
Load & & $1.8 \mathrm{~kW}$, RLC load $0-2 \mathrm{~kW}$ \\
\hline
\end{tabular}




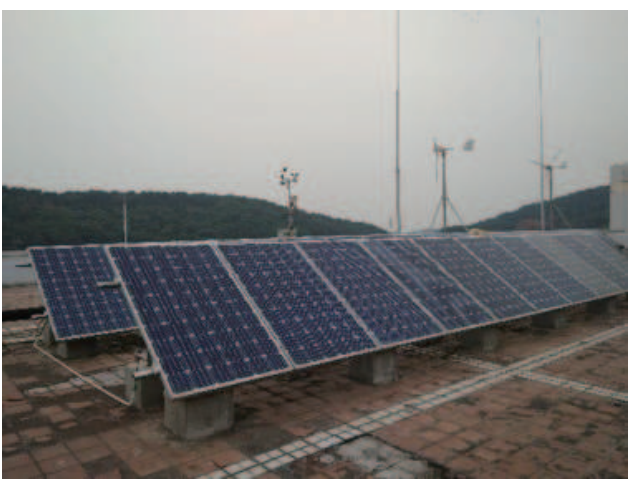

(a)

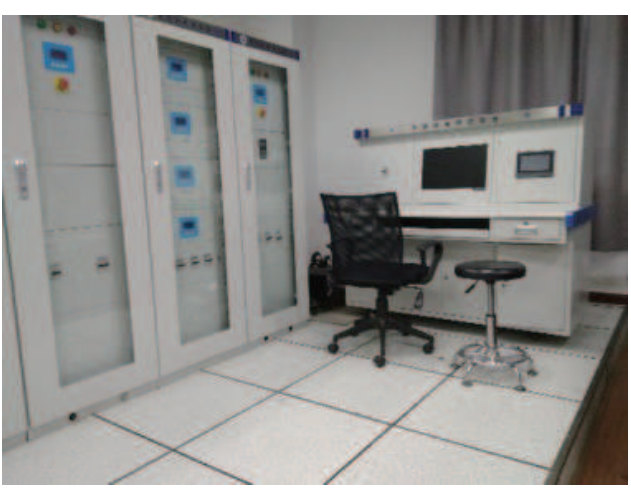

(c)

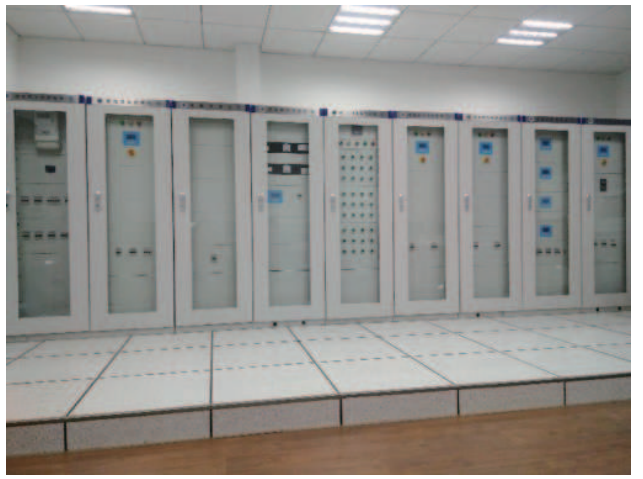

(b)

Figure 6. Off-gird microgrid system: (a) wind-solar microgrid system; (b) battery-SC hybrid energy storage system; and (c) control system.

Table 2. Configuration specification of DC converter.

\begin{tabular}{lcc}
\hline Parameters & Symbol & Value \\
\hline Maximum DC power output & $V_{d c}$ & $400 \mathrm{~V}$ \\
voltage & $L_{s}$ & $1.2 \mathrm{mH}$ \\
Transformer leakage & $C_{1}$ & $4000 \mathrm{uF}$ \\
inductance & $R_{L}$ & $10-90 \mathrm{~m} \Omega$ \\
Output capacitor & $f_{s w}$ & $20 \mathrm{kHz}$ \\
Load resistance & & $0-40 \mathrm{~A}$ \\
Switching frequcency & $\mathrm{N}$ & 5 \\
Output current & &
\end{tabular}

As shown in Figure 7a, the SOC of hybrid energy storage declines less than that of a single-battery pack SOC, and the single-cell SOC declines faster. However, in the hybrid energy-storage system, the discharge pressure of the battery can be relieved due to the addition of supercapacitors. To intuitively see the protection of the battery using a hybrid energy storage system, the battery current and the single-battery current in the hybrid energy-storage system are compared, as shown in Figure 7b. It can be seen that the battery current in the hybrid energy storage is basically at $50 \mathrm{~A}$, and the single-storage current is significantly higher than the battery current in the hybrid energy-storage system, and the high rate current will inevitably have a greater impact on the battery life, and more serious safety problems may occur. In hybrid energy storage, the supercapacitor can charge and discharge with a high-rated current, and the current of the battery charge and discharge will naturally decrease, prolonging the life of the lithium-ion battery. 


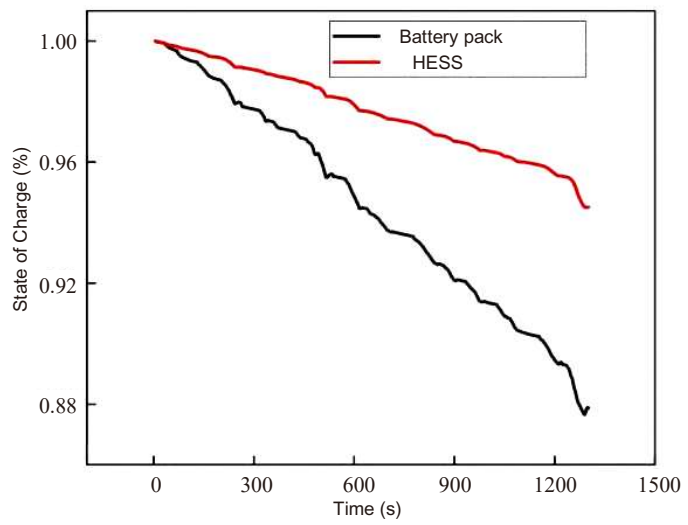

(a)

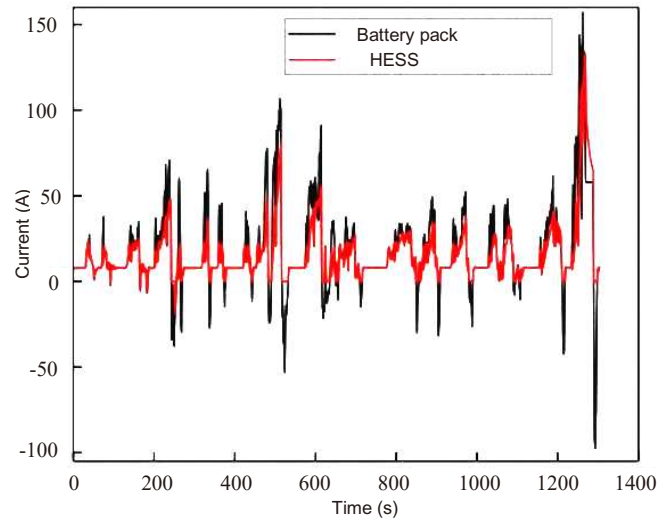

(b)

Figure 7. Experimental comparison of HESS and battery pack: (a) SOC curve of HESS and battery pack and (b) Current curve of HESS and battery pack.

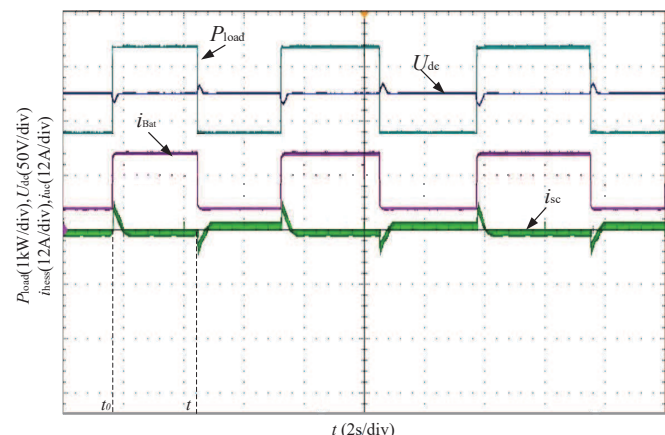

(a)

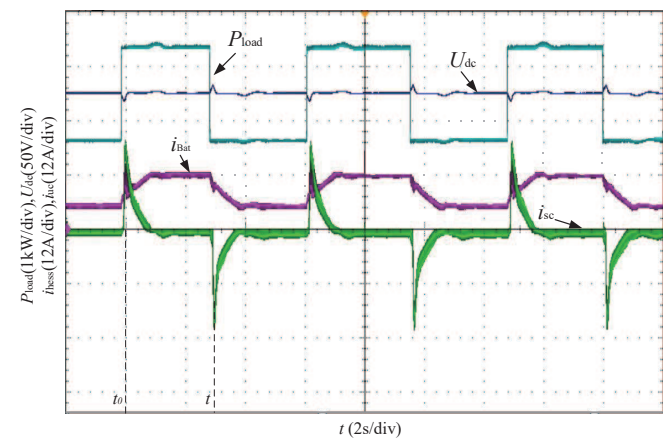

(b)

Figure 8. Experimental comparison of HESS with pulsating load: (a) without adaptive energy optimization (AEO); (b) with adaptive energy optimization (AEO).

The waveform of voltage and current of the HESS without the function of adaptive energy optimization control is shown in Figure 8a. When the load rises and falls suddenly, the current of the battery module has a sudden change caused by the limited response of the SC module, affecting the service life of the battery. In Figure $8 b$, the load power is from $1.75 \mathrm{~kW}$ and it rises up to $3.25 \mathrm{~kW}$. The battery module current $i_{b a t}$ is also from $8 \mathrm{~A}$ and it slowly rises up to around $15 \mathrm{~A}$. The SC module current $i_{s c}$, which maintains the instantaneous power compensation is around, $20 \mathrm{~A}$. When the load power increases from $1.75 \mathrm{~kW}$ to $3.25 \mathrm{~kW}$, the $i_{b a t}$ is slowly dropped from $15 \mathrm{~A}$ to around $8 \mathrm{~A}$, and the $i_{s c}$ is maintained at $20 \mathrm{~A}$. Based on the AEO, this method effectively reduced the bus voltage fluctuation of a microgrid caused by the load-demand fluctuation, and it optimized the charge/discharge control capability of HESS.

The comparative analysis of the sliding window time, the square wave period, and the SoC by experiment are shown in Figure 9a,b. The results show that the proposed AEO control strategy improved the stability of the microgrid during load demand fluctuation. Several sets of different sliding window times and the square wave period are simulated in the experiment, and $T \in\left\{0.42 T_{0}, T_{0}\right\}$. With the AEO control strategy, the performance of the battery module charging and discharging is better. Comparing Figure $9 a$ with Figure $9 b$, the square wave period $T$ is smaller, the performance of charging or discharging is effective more obvious.

The SC module terminal voltage is affected by the power loss during the process of HESS charging/discharging. The process causes the SC module terminal voltage to continuously drop. As shown in Figure 10a, it can be seen that the SC module terminal 
voltage drops by nearly $20 \mathrm{~V}$ after $100 \mathrm{~s}$. Therefore, the SC module terminal voltage needs to be kept around the reference voltage during the charging/discharging of HESS. In the same experiment environment, the SC module terminal voltage used adaptive control to maintain stability as shown in Figure 10b. By contrast analysis between Figure 10a,b, it can be seen that the SC terminal voltage adaptive control is to keep the terminal voltage around at the reference voltage.

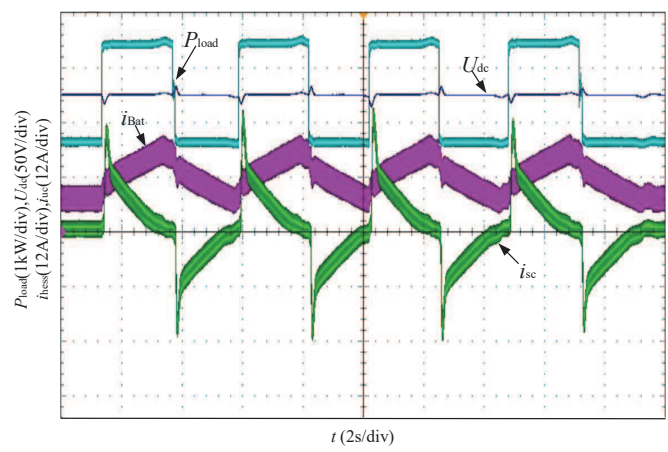

(a)

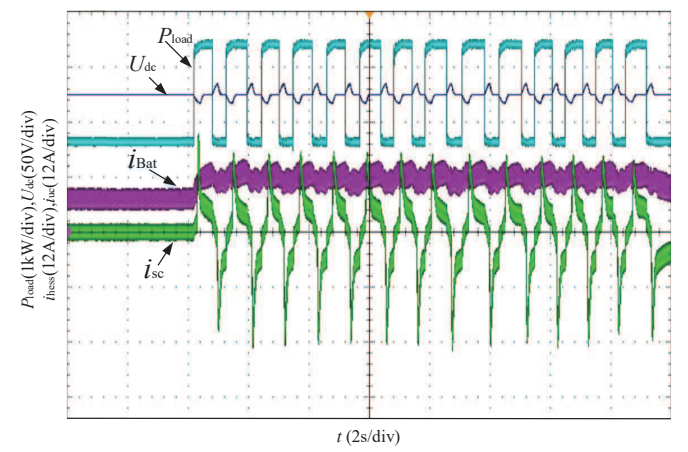

(b)

Figure 9. Experimental comparison of at different sampling time, (a) $t=2 \mathrm{~s}, t_{0}=4 \mathrm{~s} ;(\mathbf{b}) t=1.8 \mathrm{~s}$, $t_{0}=1.8 \mathrm{~s}$.

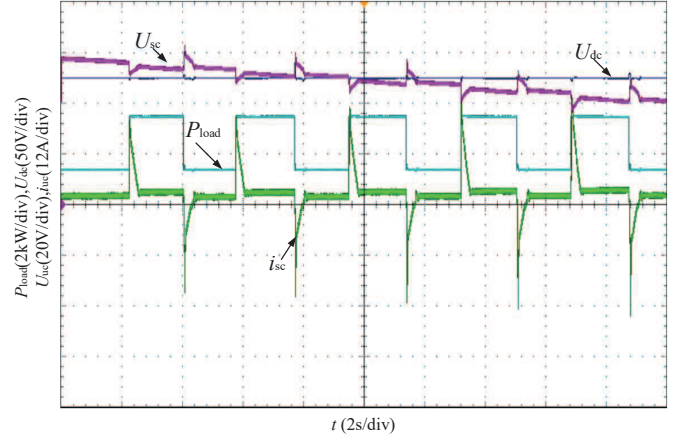

(a)

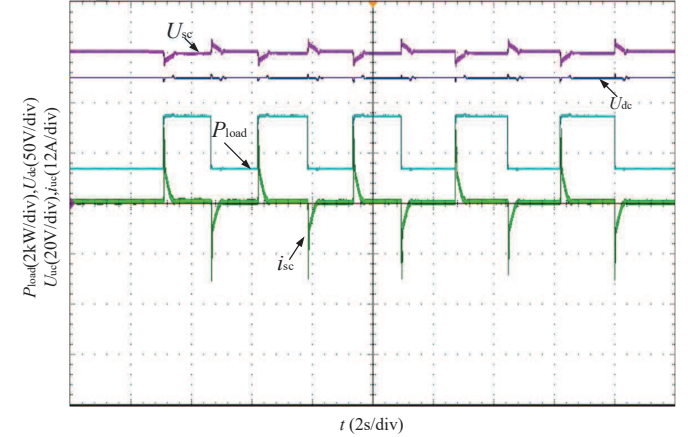

(b)

Figure 10. Experimental waveform chart with adaptive control of the SC terminal voltage: (a) without AEO; (b) with AEO.

The effectiveness of the proposed AEO control strategy is verified by model simulation and dynamic model experiments. This control strategy ensures the stability of the DC bus voltage, uses the SC to optimize the charging and discharging process of the battery to a great extent, and extends the service life of the battery. At the same time, the SC terminal voltage is controlled by adaptive control. The voltage is stable near the reference voltage value, which avoids the shutdown of the terminal voltage exceeding the limit. The HESS maintains stability and meets the load fluctuation of a microgrid during fluctuation load. The proposed AEO control strategy effectively improves the economics of energy systems.

\section{Conclusions}

In this paper, an adaptive energy optimization control strategy of HESS is studied. Aiming at the power fluctuations of the pulsating load of isolated DC microgrid, an adaptive energy-control strategy for a hybrid energy storage system based on moving average filtering algorithm is proposed, which is composed of three parts: sliding average filtering algorithm, voltage variable gain adaptive control at the supercapacitor terminal, and energy-flow equalization control algorithm of a battery pack.

The various sections of this control policy are analyzed in detail in this article, and the effectiveness of the proposed control strategy is verified through model simulation 
and actual testing. While ensuring the stability of the DC bus voltage, the control strategy uses the supercapacitor to greatly optimize the charge and discharge process of the battery and prolong the service life of the battery. At the same time, the terminal voltage of the supercapacitor is stabilized near the rated value through variable gain adaptive control, which avoids the shutdown of the terminal voltage beyond the limit. In addition, the SOC of each battery pack is controlled by energy-flow equalization convergence.

The control strategy can be applied to isolated DC microgrids with more pulsating loads or DC island microgrid, remote mountainous off-grid and other fields, which can effectively improve the economy of the whole life cycle of the system while meeting the load plug-and-play requirements.

Author Contributions: X.W. conceived the methodology, developed the theory, and performed the computations under the guidance of S.L. The results were discussed by all authors, and the final manuscript was written with contributions from all authors. All authors have read and agreed to the published version of the manuscript.

Funding: This research was funded by the Jiangxi Provincial Department of Education Science and Technology Research Project under Grant GJJ202512.

Institutional Review Board Statement: Not applicable.

Informed Consent Statement: Not applicable.

Data Availability Statement: Not applicable.

Conflicts of Interest: The authors declare no conflict of interest.

\section{Abbreviations}

The following abbreviations are used in this manuscript:

$P_{p v} \quad$ Photovoltaic generation power

$P_{S C} \quad$ Output power of Supercapacitor

$P_{b a t} \quad$ Output power of battery

$P_{\text {load } 1} \quad$ Fixed load

$P_{\text {load2 }} \quad$ Pulsating load

$U_{s c} \quad$ Supercapacitor terminal voltage

$U_{b a t} \quad$ Battery terminal voltage

$U_{d c} \quad$ DC bus voltage

$U_{s c-r e f} \quad$ Reference terminal voltage of supercapacitor

$U_{s c-\text { min }}$ Minimum terminal voltage of supercapacitor

$U_{s c-\max }$ Maximum terminal voltage of supercapacitor

$i_{\text {bat }} \quad$ Charging/discharging current of battery

$L_{i 1}-L_{i 4} \quad$ Energy storage inductance

$K_{1}-K_{4} \quad$ Protective circuit breaker

AEO Adaptive energy optimization

DG Distributed generation

DC Direct current

HESS Hybrid energy storage system

PV Photovoltaic

RES Renewable energy source

SC Supercapacitor

Bat Battey

SOC State of charge

PWM Pulse-width modulation

\section{References}

1. Yang, H.; Yin, Z; Shao, T. Control strategy of hybrid energy storage system based on virtual DC generator to suppress DC bus voltage fluctuation. J. Phys. Conf. Ser. 2021, 1848, 012114. [CrossRef]

2. Chen, M.; Zhang, J. Research on control strategy of battery-supercapacitor hybrid energy storage system based on droop control. Int. J. Low-Carbon Technol. 2021, 3, 1167990. [CrossRef] 
3. Lenka, S.; Sinha, P.; Jena, C. A Review on Power Quality İmprovement of Grid Connected PV with Lithium-Ion and Super Capacitor Based Hybrid Energy Storage System Using a New Control Strategy. Renew. Energy Optim. Plan. Control 2022, $62,7728-7737$.

4. Singh, P.; Lather, J.S. Power management and control of a grid-independent DC microgrid with hybrid energy storage system. Sustain. Energy Technol. Assess. 2021, 43, 100924. [CrossRef]

5. Enang, C.M.; Johnson, B.K. Bidirectional dc-dc converter control in battery-supercapacitor hybrid energy storage system. In Proceedings of the 2020 IEEE Power \& Energy Society Innovative Smart Grid Technologies Conference (ISGT), Washington, DC, USA, 17-20 February 2020; Volume 1, pp. 223-231.

6. Wang, K.; Wang, W.; Wang, L.; Li, L. An improved SOC control strategy for electric vehicle hybrid energy storage systems Energies 2020, 13, 5297. [CrossRef]

7. Ravada, B.R.; Tummuru, N.R.; Ande, B.N.L. Photovoltaic-Wind and Hybrid Energy Storage Integrated Multi-Source Converter Configuration for DC Microgrid Applications. IEEE Trans. Sustain. Energy 2020, 12, 83-91. [CrossRef]

8. Habeeb, S.A.; Tostado-Véliz, M.; Hasanien, H.M.; Turky, R.A.; Meteab, W.K.; Jurado, F. DC Nanogrids for Integration of Demand Response and Electric Vehicle Charging Infrastructures: Appraisal, Optimal Scheduling and Analysis. Electronics 2021, 10, 2484. [CrossRef]

9. Zhang, Q.; Wang, L.; Li, G.; Liu, Y. A real-time energy management control strategy for battery and supercapacitor hybrid energy storage systems of pure electric vehicles. J. Energy Storage 2020, 31, 101721. [CrossRef]

10. Kouchachvili, L.; Yaïci, W.; Entchev, E. Hybrid battery/supercapacitor energy storage system for the electric vehicles. J. Power Sources 2018, 374, 237-248. [CrossRef]

11. Argyrou, M.C.; Marouchos, C.C.; Kalogirou, S.A.; Christodoulides, P. Modeling a residential grid-connected PV system with battery-supercapacitor storage: Control design and stability analysis. Energy Rep. 2021, 7, 4988-5002. [CrossRef]

12. Argyrou, M.C.; Marouchos, C.C.; Kalogirou, S.A.; Christodoulides, P. A novel power management algorithm for a residential grid-connected PV system with battery-supercapacitor storage for increased self-consumption and self-sufficiency. Energy Convers. Manag. 2021, 246, 114671. [CrossRef]

13. Abdalla, A.N.; Nazir, M.S.; Tao, H.; Cao, S.; Ji, R.; Jiang, M.; Yao, L. Integration of energy storage system and renewable energy sources based on artificial intelligence: An overview. J. Energy Storage 2021, 40, 102811. [CrossRef]

14. Luo, F.; Shao, J.; Jiao, Z.; Zhang, T. Research on optimal allocation strategy of multiple energy storage in regional integrated energy system based on operation benefit increment. Int. J. Electr. Power Energy Syst. 2021, 125, 106376. [CrossRef]

15. Makhdoomi, S.; Askarzadeh, A. Impact of solar tracker and energy storage system on sizing of hybrid energy systems: A comparison between diesel/PV/PHS and diesel/PV/FC. Energy 2021, 231, 120920. [CrossRef]

16. Hong, H.; Jiang, Q. Model Predictive Control-Based Coordinated Control Algorithm with a Hybrid Energy Storage System to Smooth Wind Power Fluctuations. Energies 2019, 12, 4591. [CrossRef]

17. Katuri, R.; Rao, G.S. Design of math function based controller for smooth switching of hybrid energy storage system. Majlesi J. Electr. Eng. 2018, 12, 47-54.

18. Wegener, M.; Schneider, J.V.; Malmquist, A.; Isalgue, A.; Martin, A.; Martin, V. Techno-economic optimization model for polygeneration hybrid energy storage systems using biogas and batteries. Energy 2021, 218, 119544. [CrossRef]

19. Bai, Y.; He, H.; Li, J.; Li, S.; Wang, Y.X.; Yang, Q. Battery anti-aging control for a plug-in hybrid electric vehicle with a hierarchical optimization energy management strategy. J. Clean. Prod. 2019, 237, 117841. [CrossRef]

20. Song, Q.; Chen, J. A decentralized energy management strategy for a battery/supercapacitor hybrid energy storage system in autonomous DC microgrid. In Proceeding of the 27th IEEE International Symposium on Industrial Electronics (ISIE), Cairns, Australia, 13-15 June 2018; pp. 19-24.

21. Tobajas, J.; Garcia-Torres, F.; Roncero-Sánchez, P.; Vázquez, J.; Bellatreche, L.; Nieto, E. Resilience-oriented schedule of microgrids with hybrid energy storage system using model predictive control. Appl. Energy 2021, 306, 118092. [CrossRef]

22. Pan, C.; Tao, S.; Fan, H.; Shu, M.; Zhang, Y.; Sun, Y. Multi-objective optimization of a battery-supercapacitor hybrid energy storage system based on the concept of cyber-physical system. Electronics 2021, 15, 1801. [CrossRef]

23. Wu, X.; Cao, W.; Wang, D.; Ding, M. A Multi-Objective optimization dispatch method for microgrid energy management considering the power loss of converters. Energies 2019 12, 2160. [CrossRef]

24. Cao, M.; Xu, Q.; Nazaripouya, H.; Chu, C.C.; Pota, H.R.; Gadh, R. Engineering energy storage sizing method considering the energy conversion loss on facilitating wind power integration. IET Gen. Transm. Distrib. 2018, 13, 1693-1699. [CrossRef]

25. Jiao, Y.; Månsson, D. Analysis of Two Hybrid Energy Storage Systems in an Off-Grid Photovoltaic Microgrid: A Case Study. In Proceeding of the 2020 IEEE PES Innovative Smart Grid Technologies Europe (ISGT-Europe), The Hague, The Netherlands, 26-28 October 2020; pp. 554-558.

26. Zhang, L.; Hu, X.; Wang, Z.; Sun, F.; Dorrell, D.G. A review of supercapacitor modeling, estimation, and applications: A control/management perspective. Renew. Sustain. Energy Rev. 2018, 81, 1868-1878. [CrossRef] 